\title{
HIGH FIELD SUPERCONDUCTOR DEVELOPMENT AND UNDERSTANDING
}

\author{
A. Establishing the limits of performance of Niobium Titanium. \\ B. Establishing whether Chevrel Phase Materials can become useful high \\ field superconductors.
}

\author{
Progress Report \\ June 1st 1992 - May 31st 1993 \\ Peter J. Lee, Paul D. Jablonski, Lance D. Cooley \\ George Stejic, Laura A. Bonney, Thomas C. Willis \\ and David C. Larbalestier \\ Applied Superconductivity Center \\ University of Wisconsin at Madison
}

Prepared for

THE US DEPARTMENT OF ENERGY

DIVISION OF HIGH ENERGY PHYSICS

AGREEMENT NO. DE-FG02-91ER40643

\begin{abstract}
NOTICE
This report was prepared as an account of work sponsored by the United States Government. Neither the United States nor the Department of Energy, nor any of their employees, makes any warranty, express or implied, or assumes any legal liability or responsibility for the accuracy, completeness, or usefulness of any information, apparatus, product or process disclosed or represents that its use would not infringe privately-owned rights.
\end{abstract}


A. ESTABLISHING THE LIMITS OF PERFORMANCE

OF NIOBIUM TITANIUM

$\begin{array}{ll}\text { A.I. } & \text { Hydrostatic Extrusion Press }\end{array}$

$\begin{array}{lll}\text { A.II. } & \text { Powder Metallurgy APCs }\end{array}$

$\begin{array}{ll}\text { A.III. } & \text { APC based Flux-Pinning Studies }\end{array}$

$\begin{array}{lll}\text { A.III.a. } & \text { APC Composite Work }\end{array}$

$\begin{array}{lll}\text { A.III.b. } & \text { APC Composite Fabrication and Microstructure }\end{array}$

$\begin{array}{lll}\text { A.III.c. } & \text { Promising Electromagnetic Properties } & 8\end{array}$

$\begin{array}{lll}\text { A.III.d. } & \text { Advances in Flux Pinning Theory }\end{array}$

A.IV. The Thickness Dependence of $\mathrm{J}_{\mathrm{c}}$ in $\mathrm{Nb}$ - Ti Thin Films 10

$\begin{array}{ll}\text { A.V. } & 13\end{array}$

B. ESTABLISHING WHETHER CHEVREL PHASE MATERIALS COULD

BECOME USEFUL HIGH FIELD SUPERCONDUCTORS.

C. REFERENCES

D. PUBLICATIONS

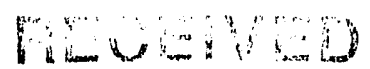

JUN 011923

OSTI 


\section{ABSTRACT}

The acquisition of a hydrostatic extrusion press now allows us to extrude composites under controlled conditions and enables us to fabricate new compusite designs. We have successfully extruded a variety of composites including powder metallurgy APCs. Our conventional APC composite has been successfully brought to the completion of its fabrication. The results of the characterization of that composite have proven to be quite exciting. There is proof that the "ideal" microstructures that are hoped for in APC composites can be made. The flux pinning force of our APC composite is stronger than that for a conventional composite, despite having about half of the volume fraction of pins and a lower $B_{c_{2}}$ than occurs in a conventional composite. Additionally, the uniform nature of the microstructure makes our APC composite well-suited for more fundamental studies of flux pinning.

We have fabricated thin film "model" conductors in order to understand basic flux-pinning mechanisms and these films have yielded interesting data on the inportance of film geometry.

Further advances have been made in increasing the $\mathrm{J}_{c}$ of Chevrel Phase conductors and a clear path is now outlined for further improvement.

A. ESTABLISHING THE LIMITS OF machine has chambers for extruding $1.25 \mathrm{in}(\sim 32 \mathrm{~mm})$ PERFORMANCE OF NIOBIUM or 0.625 in $(16 \mathrm{~mm})$ diameter with a maximum TITANIUM. extrusion pressure of $\sim 300,000 \mathrm{psi}(\sim 2 \mathrm{GPa})$. We can safely extrude to $270 \mathrm{C}$ in the bore (we have

\section{A.I. Hydrostatic Extrusion Press}

After extensive testing by Paul Jablonski the new hydrostatic extrusion press (from Naples successfully extruded billets pre-heated to $650 \mathrm{C})$. The extrusion press also features an intensifier which fills and pre-pressurizes the chamber with fluid and dies to extrude 10:1 or $25: 1$ (area ratios) for both chambers. Research) has been installed in our facilities. The 
Table I Initial $\mathrm{J}_{\mathrm{c}}$ results from trial $\mathrm{UW}$ extruded powder-APC billets.

\begin{tabular}{lclll}
\hline Sample ID & \multicolumn{3}{l}{$\mathrm{J}_{\mathrm{c}}\left(\mathrm{A} / \mathrm{mm}^{2}\right), 4.2 \mathrm{~K}$} & \multicolumn{2}{l}{ Description } \\
\cline { 2 - 4 } & $4 \mathrm{~T}$ & $5 \mathrm{~T}$ & $6 \mathrm{~T}$ & \\
\hline $920304-4(91)$ & 1700 & 1341 & 1018 & $(\mathrm{Nb}-46.5 \mathrm{Ti}+20 \mathrm{vol} . \% \mathrm{Nb})$ \\
$920506-4(91)$ & 2245 & 1351 & 652 & $(\mathrm{Nb}-46.5 \mathrm{Ti}+40 \mathrm{vol} \% \mathrm{Nb})$ \\
$921003-(91)$ & 2257 & 1407 & 852 & $(\mathrm{Nb}-55 \mathrm{Ti}+20 \mathrm{vol} . \% \mathrm{Nb})$ \\
$930114-20(91)$ & 1760 & 1102 & 660 & $(\mathrm{Nb}-55 \mathrm{Ti}+20 \mathrm{vol} \% \mathrm{Nb})$ \\
\hline \hline
\end{tabular}

In order to fully utilize our new extrusion facilities Paul Jablonski has developed capabilities to fabricate evacuated extrusion billets in house and has trained undergraduates in their use.

The hydrostatic extrusion press promises to be an exciting tool for exploring alternative pinning center materials, and designs and also for the examination of more basic but important conventional design parameters such as diffusion barrier fabrication methods and the influence of extrusion conditions on strain state.

\section{A.ll. Powder Metallurgy APCs}

The first billets to be extruded using the new hydrostatic extrusion press were Paul Jablonski's powder metallurgy, PM, based APC composites. Not only were sintered powder based billets successfully extruded but also, as will be described below, loose powder based billets! In Table I some initial critical current data from PM-APC composites are given.

While these results are encouraging (they are within a factor of about 2-3 of the best $\mathrm{J}_{c}$ for $\mathrm{Nb}-\mathrm{Ti}$ in wire form), all are extrinsically limited as exhibited by both the low $n$-values and by broken filaments found upon etching the copper away. A potentially more serious problem was encountered during processing of other sections of the first two alloys listed above. The monofilaments had been part of a $2^{5}$ fractional factorial experiment designed to identify the important factors for extruding these materials. The starting materials had come from two PM billets processed in the usual manner. These processed well as both mono and multi-filaments until the multifilament reached 0.045 in diameter at which stage they promptly 


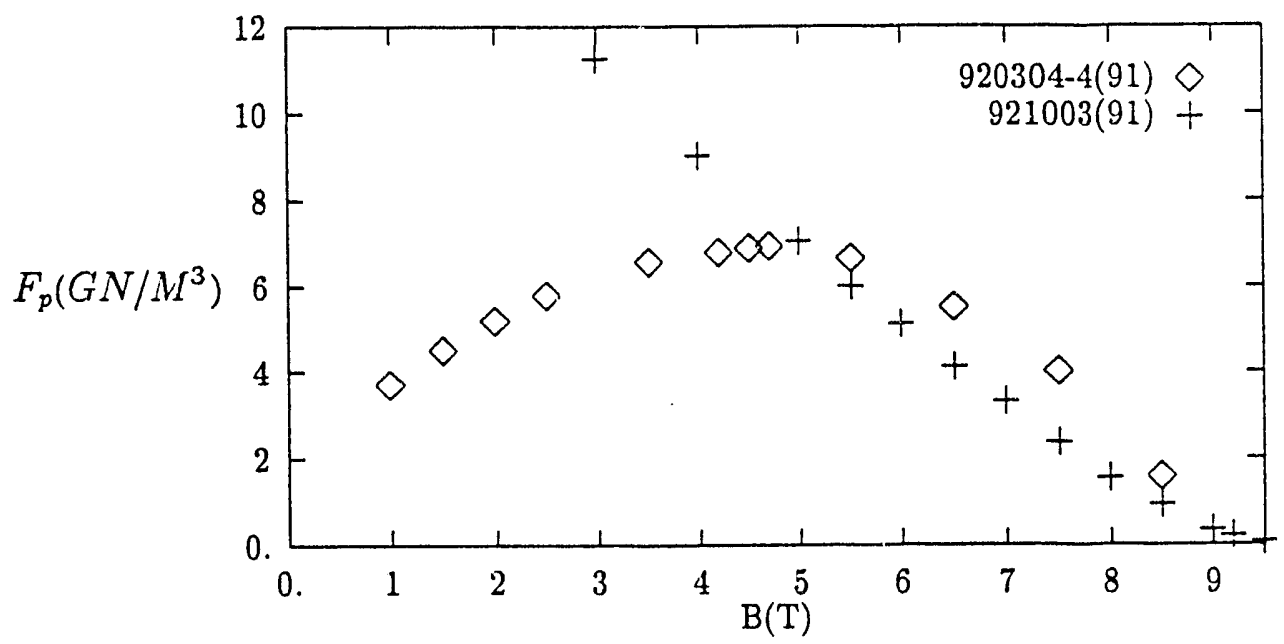

Figure 1 Flux pinning curves deduced from $\mathrm{J}_{\mathrm{ct}}$ results. Note that wires have 91 filaments; however, some filaments are probably broken and these conductors have low nvalues. Composite $920304-4(91)$ is $\mathrm{Nb}-46.5 \mathrm{wt} . \% \mathrm{Ti}+20$ vol.\% Nb, pressed and sintered before extrusion and composite $921003(91)$ is $\mathrm{Nb}-55 \mathrm{wt} . \% \mathrm{Ti}+20 \mathrm{vol} . \%$ $\mathrm{Nb}$, powders canned and extruded without sintering.

broke into short sections. Upon inspection, non-deformable particles were found to initiate the failures (later it was found that these particles contained high levels of $\mathrm{Ni}, \mathrm{V}$, or $\mathrm{Fe}$ ). Apparently, the particles were included in the starting powders (the last two composites listed above did not have these hard particles in them). An empirical solid solutioning heat-treatment was devised; this was successful enough to produce the results shown in Table I.

It is worth noting that the last two composites listed had not been sintered, instead they were extruded from loose powder. The ability to form a monofilament by extruding canned loose powder gives us even more flexibility for composite fabrication and pinning center selection.

While the broken filaments prevent us from making good $\mathrm{J}_{c}$ comparisons, it is interesting to compare the flux pinning curves in the "optimized" sintered vs. loose powder starting monofilaments (Figure 1). While the sintered material behaves quite similarly to conventional $\mathrm{Nb}-\mathrm{Ti}$ with a peak $\mathrm{F}_{p}$ at $b=0.5$ the loose powder material has a very low field peak (not reached in Figure 1). While these results are preliminary, we feel that the low field peak may be indicative of surface pinning, i.e., the pinning centers are not optimized, thus higher $J_{c}$ 's may be possible. Non-extrinsically limited material will be 


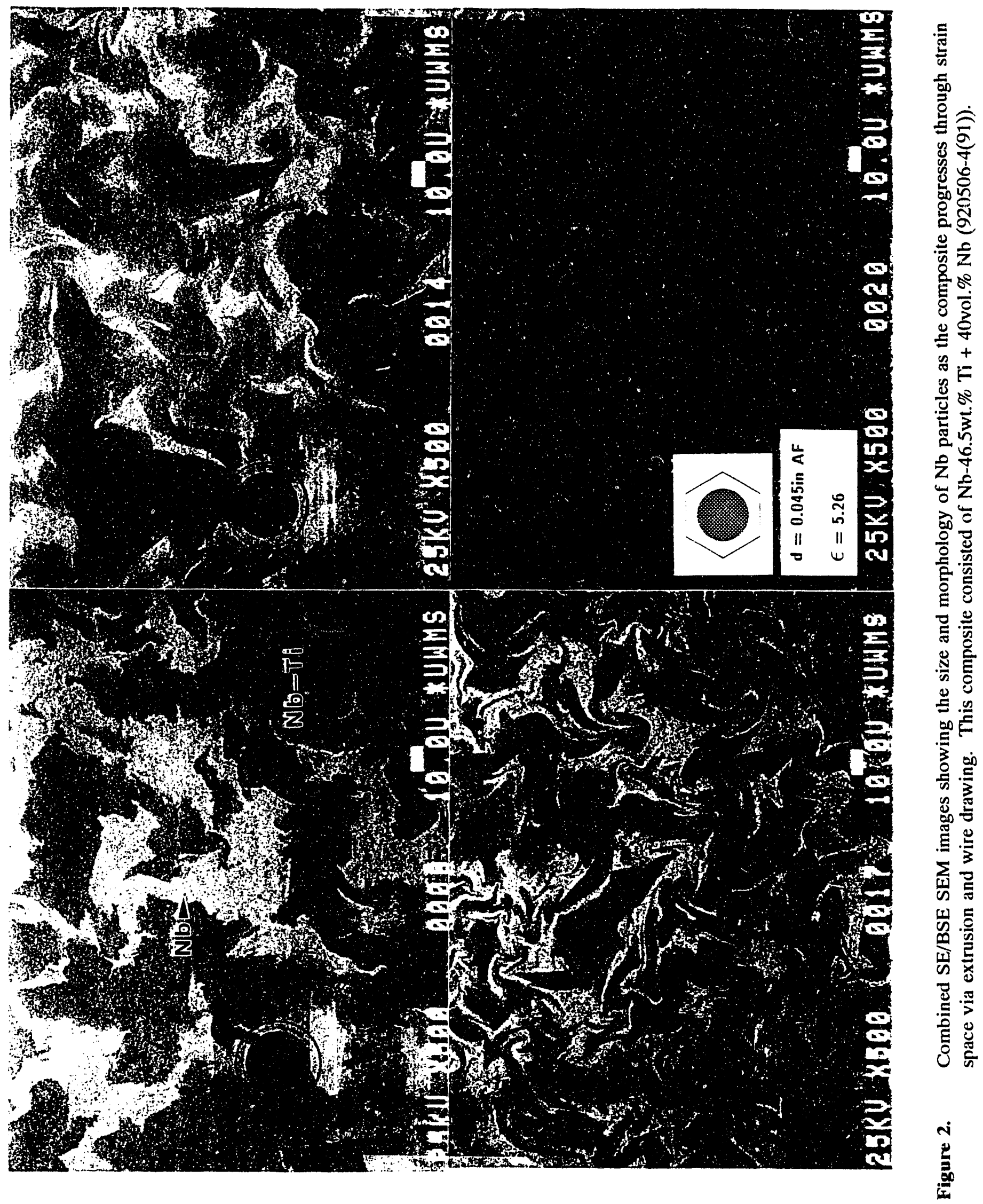




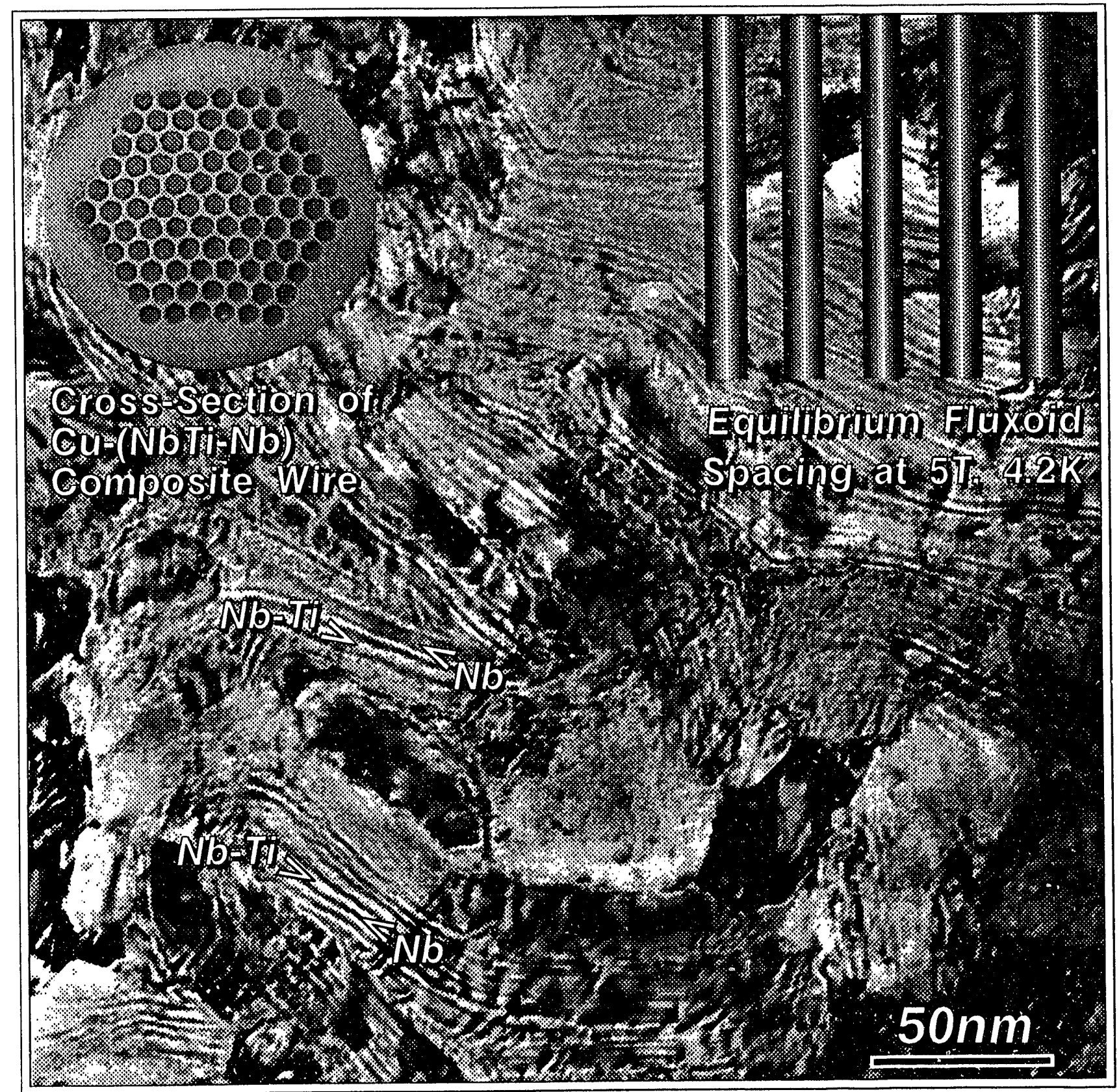

Figure 3 TEM micrograph of a transverse cross-section of a powder-APC Nb-46.5wt.\%Ti + $40 \mathrm{vol} . \% \mathrm{Nb}$ filament at a total strain of 13.2 .

required in order to verify this.

The deformation of the pinning centers was monitored by SEM and TEM techniques. The shape development of the $\mathrm{Nb}$ particles into ribbons by the plane strain deformation mode is illustrated in
Figure 2. In Figure 3 we compare the very fine scale of pinning center achieved with the equilibrium fluxoid spacing at $5 \mathrm{~T}(4.2 \mathrm{~K})$. 
Progress Report June 1st 1992 - May 31st 1993, DE-FG02-91ER40643, University of Wisconsin-Madison

\section{A.III. APC based Flux-Pinning Studies}

Significant advances have been reported during the past year throughout the community of researchers who are involved with artificial pinning center (APC) composite research. The maximum flux pinning force has been pushed to $28 \mathrm{GN} / \mathrm{m}^{3}$ at $2.25 \mathrm{~T}^{1}$, and the problem of the degradation of $\mathrm{B}_{c_{2}}$ has begun to receive attention ${ }^{1,2}$.

The past year has also seen the completion of our APC composite research. Much of that research is directly applicable to the accelerator magnet program, in particular the knowledge that has been gained concerning the fabrication and flux pinning issues. Additionally, by taking advantage of the model geometry of the microstructure of our APC composite, L. Cooley has been able to undertake a detailed analysis of more fundamental flux pinning issues in his thesis project, which has also been completed in the past year. This work has generated a major publication and a Materials Research Society graduate student award, and there are several forthcoming publications related to this work being planned.

\section{A.III.b. APC Composite Fabrication and} Microstructure.

We described in our previous report how mechanical difficulties had been blocking the fabrication of our APC composite to final size. In particular, it was mentioned how the anomalous hardening rate of the $\mathrm{Nb}-1.3 \mathrm{wt} \% \mathrm{Ti}$ pins, the variation in the hardness of the composite across its crosssection, and the overall high hardness values may have contributed to the processing difficulties.

We are happy to report that these obstacles have been partly overcome, enabling the processing of the composite to proceed to final size. In addition to L. Cooley, the most significant contribution to this achievement has been made by P. Jablonski. In reevaluating their fabrication process, the schedule of area reduction for the drawing process, the geometry (die half-angle) of the dies, the geometry of the stack, the hardness of the stabilizer, and the hardness data previously mentioned emerged as key parameters. Small alterations in the process, such as moving 
toward at $10 \%$ area reduction schedule (instead of the standard $20 \%$ schedule) when drawing a stack at large size, and using a 7-stack at the final stage instead of a 61-stack, proved to be beneficial, although the drawability problems have not been solved. Certainly, the piece length for this experimental composite is comparable to that of some of the commercial APC composites, and much worse than others. This emphasizes that the drawability of APC composites is still a major area of concern.

In a forthcoming publication ${ }^{3}$, transmission electron microscopy (TEM) of our APC composite will be presented. This verifies, for the first time, that the model geometries that are hoped can actually be achieved in APC composites. The starting geometry of the APC billet is almost perfectly preserved at a pin diameter of $100 \mathrm{~nm}$. Whereas the onset of shape instabilities is evident at an effective pin diameter of $30 \mathrm{~nm}$. Nevertheless, the hexagonal geometry of the pins is still relatively intact, as indicated in figure (centroid), when the positions of the centroids of the pins are analyzed.
A.III.c. Promising Electromagnetic Properties.

The highly-uniform APC composite microstructure allows the pins to be very efficiently used. A maximum bulk pinning force of $22 \mathrm{GN} / \mathrm{m}^{3}$ is achieved in our composite at a pin diameter of $28 \mathrm{~nm}$, despite having only $12.5 \mathrm{vol} \%$ of points and $\mathrm{a}_{c_{2}}$ of 9.7 $\mathrm{T}$ at that size (as compared to $20 \mathrm{vol} \%$ and $11 \mathrm{~T}$ for conventional $\mathrm{Nb} 47 \mathrm{wt} \% \mathrm{Ti}$ ). In fact, if the reduction of $B_{c_{2}}$ is taken into account, the maximum pinning force occurs when the pin diameter is $14 \mathrm{~nm}$, nearly equal to the diameter of the fluxon core. This is consistent with the theoretical understanding of flux pinning, contrary to the situation for a conventional composite, as has been noted in our previous reports.

The reduction of $\mathrm{B}_{c_{2}}$ remains a chief obstacle to the achievement of strong pinning forces at high ( $\geq$ $5 \mathrm{~T}$ ) fields in APC composites. The value of $\mathrm{B}_{c_{2}}$ of our APC composite decreases to the value that is representative of a $\mathrm{Nb} 34 \mathrm{wt} \% \mathrm{Ti}(7.7 \mathrm{~T}$,), which is the overall composition of the composite. Whereas, the $T_{c}$ remained near $9 K$. Our data is consistent with the trend that has been seen by other researchers. This special case of the proximity effect, where both 
the pins and the matrix have a high $\mathrm{T}_{c}$, should allow a high value of $B_{c_{2}}$ to be reached if the overall composition is given consideration.

Despite the onset of shape instabilities in the microstructure, there is electromagnetic evidence that the pinning potential is indeed still uniform and periodic down to a $17 \mathrm{~nm}$ pin diameter. The evidence is in the form of temperature-independent structure of the pinning force curves, which is an indication that the flux lattice is matching to the underlying pin geometry. This is indicated in figure (match). For this situation to occur, the short-range core pinning force should be periodic over a length comparable to the long-range inter-fluxon forces, which implies that the microstructure is uniform and periodic over a 10-30 $\mathrm{nm}$ scale. However, the degree of microstructural uniformity that is required seems not to be so extreme, as indicated by TEM, which is ccntrary to our initial expectations.

In summary, the electromagnetic properties suggest that the desired strong flux pinning can be obtained even if the volume fraction of pins is low. A low pin fraction might be a necessary component of a solution to the proximity effect problem, along with the consideration of the overall composition of the composite. Also, the data suggest that APC designs that strictly control the geometry of the pins might not be needed, opening the area of APS composite fabrication to processes that are inherently more random, such as the powder metallurgy and insitu processes.

\section{A.III.d. Advances in Flux Pinning Theory}

By virtue of the uniform geometry of the APC composite, a model system is created in which the distribution of the elementary flux pinning forces $\left(f_{p}\right)$ is very narrow. This strongly contrasts with the picture for conventional $\mathrm{Nb}-\mathrm{Ti}$, as well as some APC composites $^{4}$, whose non-uniform microstructures suggest that a broader distribution applies. We have addressed the possible effects of both regimes on the bulk flux pinning force $\left(F_{p}\right)$, and the nature of the bulk pinning force curve $\left(\mathrm{F}_{p}(\mathrm{~B})\right)$, over the past year.

In the case of a broad distribution of $f_{p}$, we think the nature of summation is changed, as explained in our recent publication ${ }^{5}$. The model we have proposed suggests that the shape of the $F_{p}(b)$ curve can change, as the temperature or pin dimension 
is changed, even though the elementary flux pinning mechanism does not change. This contradicts the widely-held understanding that when the shape of the $F_{p}(B)$ curve changes, the contributions of more than one pinning mechanism must be present. Indeed, that more traditional understanding has been the source of great confusion for us in the past: In our 1989 report, the work of C. Meingast indicated that precisely where the experimental evidence was most strongly in favor of only the core pinning mechanism operating, the shape of the $F_{p}(b)$ curve had shifted to an unexpected function. Conversely, where the shape of the $F_{p}(B)$ curve was expected, there was evidence for the operation of more than one pinning mechanism. These issues have now been more satisfactorily resolved

The thesis work of L. Cooley, scheduled to be finished in May of this year, continues the application of our model to the narrow-distribution regime. We find that even in this limit, the shape of the $F_{p}(B)$ curve changes, but in this case there is evidence to suggest that this is an intrinsic property of the pinning mechanism. The preliminary conclusion from this work indicate that the proximity effect again plays a role, causing the field dependence of $f_{p}$ to be have an unexpecied exponential component at low field. This subsequently causes the value of $f_{p}$ to be reduced, and offers a more concrete explanation whey the high current densities that we have achieved in the $\mathrm{Nb}-\mathrm{Ti}$ system, even the very large currents reported at low field in APC composites, are only 3-10 percent of the thermodynamic limit.

\section{A.IV. The Thickness Dependence of $J_{c}$ in $\mathrm{Nb}-\mathrm{Ti}$ Thin Films}

The high $J_{c}$ results found in HTS thin films have opened questions as to the nature of $J_{c}$ in those films. The commonly held view is that these results are an indication that strong flux pinning is possible in such films. However, the pinning centers responsible for the extraordinary $\mathrm{J}_{\mathrm{c}}$ values, in the HTS films, have not been definitively identified. In addition, while the thin films and bulk single crystals are very different $J_{c}$ values, both systems, nonetheless, have identical normal state resistivities. This suggests that conventional flux pinning can not be used to interpret these results, since we would expect that $J_{c}$ should be proportional to the resistivity. Instead, the 
high $J_{c}$ values of thin films may be a result of their geometry.

Over that past two years, we have explored the effect that the film geometry has upon $J_{c}$ from a theoretical and experimental vantage points. We have concluded from our theoretical work that the $J_{c}$ values are strong functions of two geometric properties of the film. The first is orientation of the film in the magnetic field. As a film is rotated in a field, the $J_{c}$ value peaks very sharply in parallel field. This result has been seen in the HTS films and has been taken as evidence for "Intrinsic Pinning". However, our isotropic Nb-Ti films exhibit the same peak in parallel field. The second geometric property effecting $J_{c}$ in thin films is the film thickness $(d)$. Our calculations predict that the $\mathrm{J}_{\mathrm{c}}$ values in parallel field should have a $1 / d$ dependence on thickness and the experimental results supporting this calculation are presented here.

We have fabricated a set of five $\mathrm{Nb}$ $47 \mathrm{wt} \% \mathrm{Ti}$ thin films of varying thicknesses with $(d=$ $60 \mathrm{~nm}, 120 \mathrm{~nm}, 250 \mathrm{~nm}, 500 \mathrm{~nm}, 1000 \mathrm{~nm}$ or $d=1 / 4 l$, $1 / 2 l, 1 l, 2 l, 4 l) . \mathrm{Nb}$-Ti was the material selected for this experiment because of its isotropic superconducting properties, its relatively wellunderstood flux pinnirig behavior and it ease of sputtering. These films were DC magnetron sputtered from a $\mathrm{Nb}-47 \mathrm{wt} \% \mathrm{Ti}$ target onto glass substrates and subsequently patterned with a $3 \mathrm{~mm}$ long by $50 \mathrm{~mm}$ wide bridge pattern for $\mathrm{J}_{\mathrm{c}}$ testing.

Using a goniometer, these films were precisely aligned in the field so that the film surface was parallel to the applied field. In this orientation, the field dependence of $\mathbf{J}_{\mathbf{c}}$ was measured for each of the five films. From this data, we plot, in Figure 4, the $J_{c}$ values at each field as a function of the log of the film thickness. The dashed lines represent the a $1 / d$ functional dependence. These results support our theoretical prediction that $J_{c}$ is inversely proportional to $d$.

These experiments, along with our previous studies on the orientational dependence of $J_{c}$, have the following implications for understanding the $\mathrm{J}_{\mathrm{c}}$ values of thin films, 


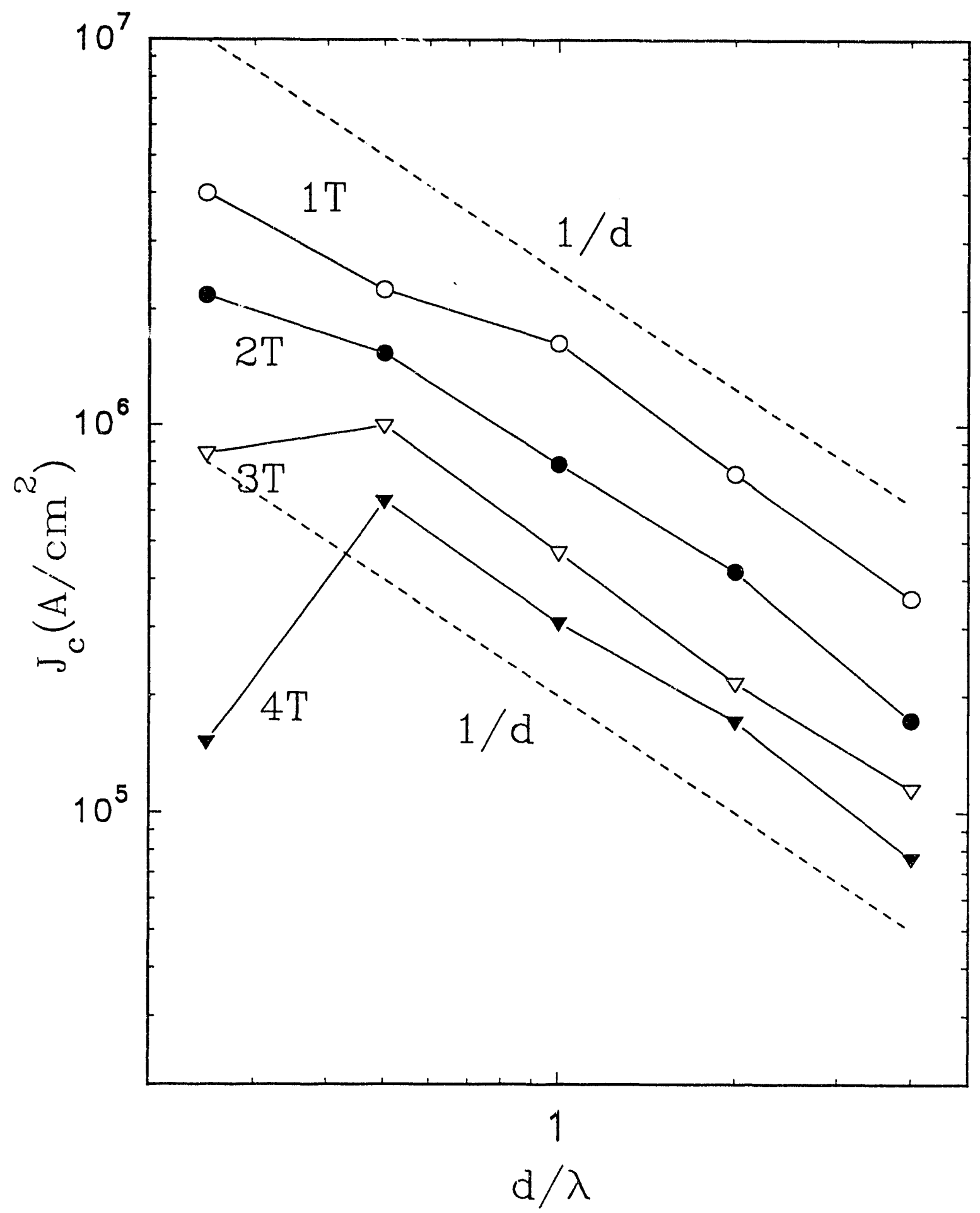

Figure 4 The $\log$ of the $\mathrm{J}_{\mathrm{c}}$ values at $1 \mathrm{~T}, 2 \mathrm{~T}, 3 \mathrm{~T}$ and $4 \mathrm{~T}$ are plotted as a function of the $\log$ of film thickness $(d / l)$. These results show that $J_{c} \sim 1 / d$. 
including the HTS films:

1. By fabricating films with $d<l$, very high $\mathrm{J}_{\mathrm{c}}$ values are possible even in relatively weak pinning materials.

2. $\mathrm{J}_{\mathrm{c}}$ is inversely proportional to $d$. $\mathrm{J}_{\mathrm{c}} \sim 1 / d$.

3. The interpretations of the $J_{c}$ values of HTS thin films must consider the effect of geometry.

\section{A.V. Undergraduate Training}

An important part of our work has always been the training of undergraduates in superconducting technology. Robert Heussner's undergraduate work on the relationship between $\mathrm{Nb}-\mathrm{Ti}$ grain size and diffusion barrier deformation has been very useful in explaining the behavior of fine filament $\mathrm{Nb}-\mathrm{Ti}$ composites. $^{6}$ He found a increase in barrier non-uniformity with $\mathrm{Nb}-\mathrm{Ti}$ grain size and a linear relationship between the coefficicnt of variance for the barrier thickness and true strain. He also found that hot extrusion resulted in a very much increased barrier non-uniformity compared with col-worked material.

Two expanded undergraduate projects have been accepted for presentation at a I.CMCCEC 1993. Craig Christopherson has been examining the effect of grain size on the strain-hardening rate of $\mathrm{Nb}-46.5 \mathrm{wt} \% \mathrm{Ti}$. The aim of this work is to develop a low-cos technique to determine the crucial strain state of $\mathrm{Nb}-\mathrm{Ti}$ composite wires, especially after extrusion. $^{7}$ Jon Ponti has been examining the effect of powder mesh size on the copper/superconductor interface regularity in $\mathrm{Cu} / \mathrm{PM} \quad \mathrm{Nb}-46.5 \quad$ wt.\% $\quad \mathrm{Ti}$ superconducting composites. He has shown how the grain size in a sintered $\mathrm{Nb}$ - $\mathrm{Ti}$ billet can be controlled and the effect of the grain size on the $\mathrm{Cu} /$ superconductor interface uniformity. This work is important in our efforts to minimizing the extrinsic limitations in PM based APC Nb-Ti conductors. 
Progress Report June Ist 1992 - May 31st 1993, DE-FG02-91ER40643, University of Wisconsin-Madison

B. ESTABLISHING WHETHER the dominant mechanism in well connected CHEVREL PHASE MATERIALS Chevrel Phase material.

COULD BECOME USEFUL HIGH To test whether grain size refinement is the key FIELD SUPERCONDUCTORS. to higher $\mathrm{J}_{\mathrm{c}}$ in Chevrel Phase materials, Bonney has been performing experiments which compare

In order for Chevrel Phase based grain size and $\mathrm{J}_{c}$ in $\mathrm{SnMo}_{6} \mathrm{~S}_{8 .}{ }^{12}$ Results indicate conductors to become useful high field that $\mathrm{J}_{\mathrm{c}}$ is proportional to grain boundary length conductors the $\mathrm{J}_{c}$ above $15 \mathrm{~T}$ (where the $\mathrm{J}_{c}$ of $\mathrm{Nb}_{3} \mathrm{Sn}$ falls rapidly) needs to be raised by 2 to 5 times current values. Initially there was concern that Chevrel Phase material was intrinsically electromagnetically granular making this goal unfeasible. Recent advances in fabrication techniques, however, that we reported on in our last progress report, have shown that well connected grains can be produced. $^{8.9}$ Earlier work on a previous generation of material had suggested that $\mathrm{J}_{c}$ values could be increased by reducing the grain size. ${ }^{10,11}$ The suggestion of these results was that the $\mathrm{J}_{\mathrm{c}}$ of Chevrel Phase conductors was controlled by flux-pinning in the grain boundaries. Clearly it was important to see if flux-pinning in the grain boundaries remained 
These results have therefore clearly

indicated the future direction of Chevrel phase

superconductor development. Bonney and

Willis have produced oxygen-free, well

connected Chevrel phase material they has

achieved $J_{\mathrm{c}}$ and $T_{\mathrm{c}}$ values equivalent to the best

yet reported (Figure 5).

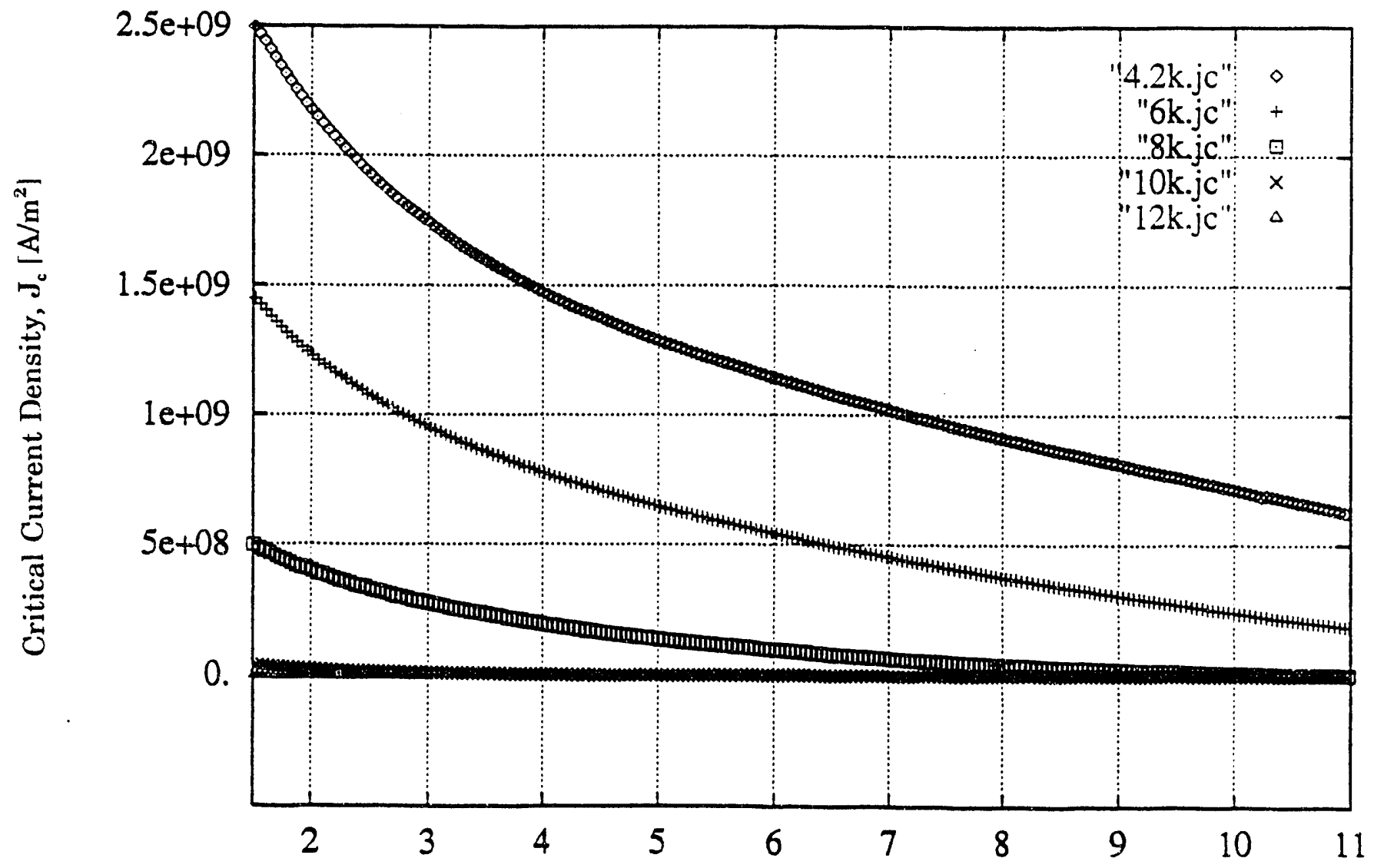

Field B [Tesla]

Figure 5 Critical current densities of HIP'ed $\mathrm{Pb}_{0.8} \mathrm{Sn}_{0.2} \mathrm{Mo}_{6} \mathrm{~S}_{8}$ sample prepared at $\mathrm{UW}$, measured at temperatures of $4.2,6,8,10$, and $12 \mathrm{~K}$. 


\section{REFERENCES}

1. K. Matsumoto, et.al., IEEE Trans. Mag. 29 (1993 to appear).

2. Leszek R. Motowidlo, Bruce A. Zeitlin, Michael S. Walker, and Pradeep Haldar, Appl. Phys. Lett. 61:991 (1992).

3. L.D. Cooley, P.J. Lee, and D.C. Larbalestier, Appl. Phys. Lett. (submitted).

4. L.d. Cooley, P.J. Lee, and D.C. Larbalestier, IEEE Trans. Mag. 27:1096 (1991).

5. L.D. Cooley, G. Stejic, and D.C. Larbalestier, Phys. Rev. B 46:2964 (1992).

6. R.W. Heussner, P.J. Lee, and D.C. Larbalestier, "Mechanical deformation of the Nb diffusion barrier in monofilamentary $\mathrm{Nb}-\mathrm{Ti}$ wire," paper LOD-10 presented at the Applied Superconductivity Conference, Chicago, Il, August 1992, to appear in Trans. Appl. Superconductivity, vol. 2 or 3, 1993.

7. J.A. Farrell, P.J. Lee, and D.C. Larbalestier, "Cold work loss during the extrusion of SSC Phase II R\&D composites as measured by microhardness," paper LOD-4 presented at the Applied Superconductivity Conference, Chicago, IL, August 1992.

8. H. Yamasaki, M. Umeda, S. Kosaka, Y. Kimura, T. C. Willis and D. C. Larbalestier, "Poor intergrain connectivity of $\mathrm{PbMo}_{6} \mathrm{~S}_{8}$ in sintered Mo-sheathed wires and the beneficial effect of hot-isostatic treatments on the transport critical current density," J. Appl. Phys., vol. 20 (3), pp 16C6-1613, 1991.

9. L. Le Lay, T.C. Willis, and D.C. Larbalestier, "Fully connected bulk $\mathrm{Pb}_{1 \cdot \mathrm{x}} \mathrm{Sn}_{\mathrm{x}} \mathrm{Mo}_{6} \mathrm{~S}_{7.6}$ samples made by hot isostatic pressing," Appl. Phys. Lett. vol. 60:6, pps: 775-777, 1992.

10. V. R. Karasik, M. O. Rikel', T. G. Togonidze, and V. I. Tsebro, "Investigation of current carrying capacity of bulk single-phase $\mathrm{PbMo}_{6} \mathrm{~S}_{8}$ samples with grains of $\approx 0.1 \mu \mathrm{m}$ size," Sov. Phys. Solid State, vol. 27, pp. 1889-1890, 1985.

11. C. Rossel and $\varnothing$. Fischer, "Critical currents in bulk Chevrel-phase samples," J. Phys. F:Metal Phys., vol. 14, pp. 455-472, 1984.

12. L.A. Bonney, T.C. Willis, and D.C. Larbalestier, "Grain Size Dependence of Critical Current Densities in Hot Isostatically pressed $\mathrm{SnMo}_{6} \mathrm{~S}_{8}$," to be published in IEEE Transactions on Applied Superconductivity, vol. 3, 1993. 


\section{PUBLICATIONS}

L. D. Cooley, G. Stejic and D. C. Larbalestier, Statistical variations of the Elementary Flux Pinning Force and their effect on the Shape of the Bulk Pinning Force Curve of High Field Superconductors, submitted to Phys. Rev. B, 1992.

L. D. Cooley, G. Stejic, D. C. Larbalestier and S. Takàcs, Direct Summation of Elementary Pinning Forces for $\mathrm{Nb}$-Ti Superconductors with a Field Dependent Probability Function, Supercon. Sci. Technol., 5, pp:97-100, 1992.

R.W. Heussner, P.J. Lee, and D.C. Larbalestier, "Mechanical deformation of the $\mathrm{Nb}$ diffusion barrier in monofilamentary Nb-Ti wire," to be published in IEEE Transactions on Applied Superconductivity, $\underline{3}, 1993$.

P. J. Lee, D. C. Larbalestier, J. C. McKinnell and A. D. McInturff, "Microstructure property relationships in Nb-Ti-Ta," to appear in Trans. Appl. Superconductivity, vol. 3, 1993.

J.A. Parrell, P.J. Lee, and D.C. Larbalestier, "Cold work loss during the extrusion of SSC Phase II R\&D composites as measured by microhardness", paper LOD-4 presented at the Applied Superconductivity Conference, Chicago, IL, August 1992, to appear in Trans. Appl. Superconductivity, vol. 3, 1993.

G. Stejic, L. D. Cooley, R. Joynt, D. C. Larbalestier and S. Takàcs, "Numerical Calculation 
of Flux Pinning by $\alpha$-Ti Precipitates in Nb-Ti," Supercond. Sci. Technol. vol. 5, pp:176-179, 1992.

P. J. Lee and D. C. Larbalestier, Niobium-Titanium Alloys, in the Concise Encyclopedia of Magnetic \& Superconducting Materials, ed. J. E. Evetts, Pergamon Press, Oxford, pp:357-363, 1992.

“Composite Superconductors," ed. S. Ochiai, K. Osamura, T. Matsushita, P. J. Lee, to be published by Marcel Dekker, New York, 1993.

L.A. Bonney, T.C. Willis, and D.C. Larbalestier, "Grain Size Dependence of Critical Current Densities in Hot Isostatically Pressed $\mathrm{SnMo}_{6} \mathrm{~S}_{8}$," to be published in IEEE Transactions on Applied Superconductivity, vol. 3, 1993. 

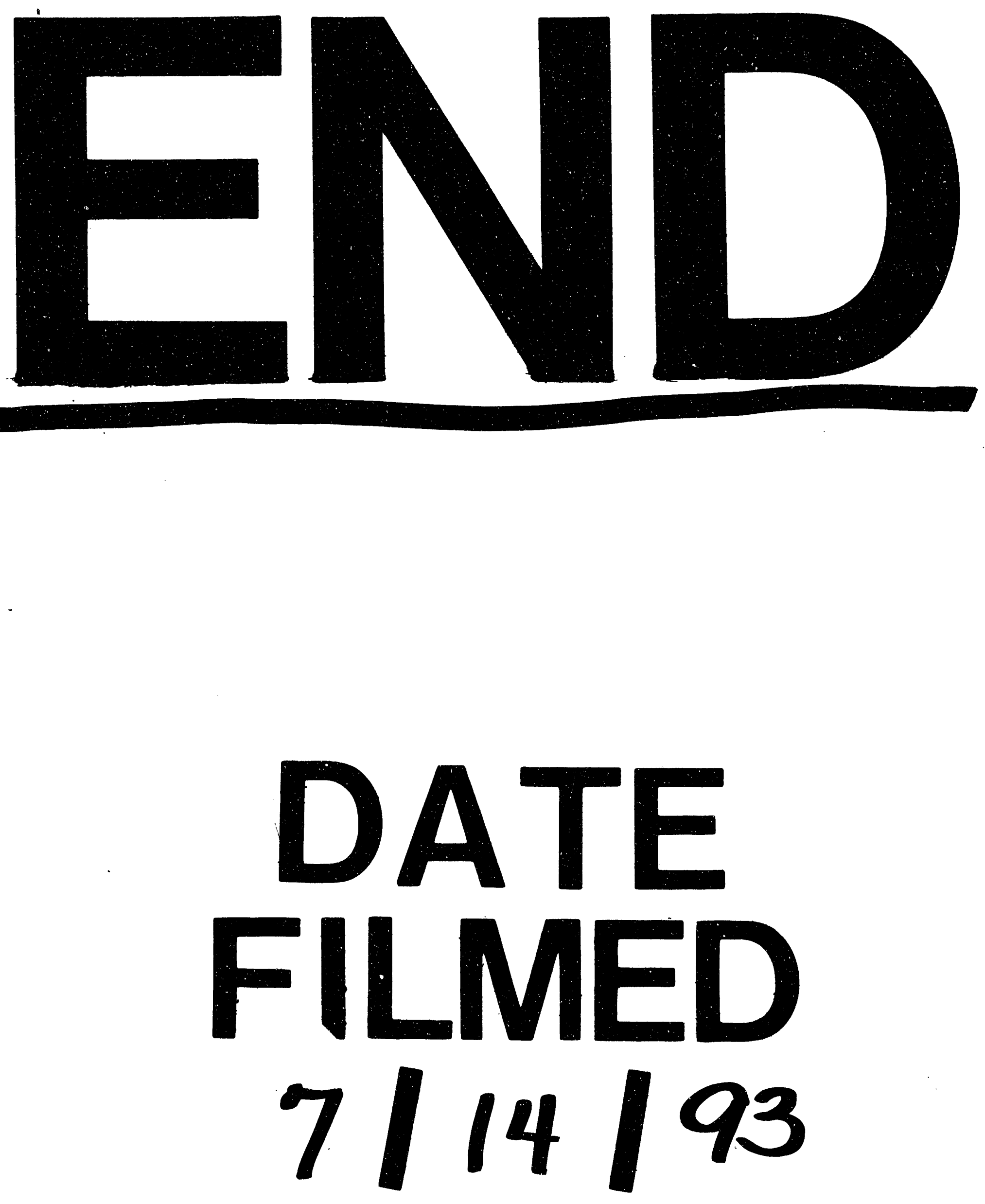
